\title{
Rate of Plagiarism in Personal Comments Essays of Applicants to a US Allopathic Medical School: an Observational Study
}

\author{
Linda S. Nield, $M D^{7}$, Manuel C. Vallejo, MD, DMD' , Anna M. Lama, MA', \\ Kristopher K. Yoon, MD², Alyson S. Carpenter, MA' , Christina M. Baker, BSW', and \\ Gerald R. Hobbs, $P h D^{7}$
}

'Department of Medical Education, West Virginia University School of Medicine, Morgantown WV, USA; '2Department of Medicine, David Geffen School of Medicine, University of California Los Angeles, Los Angeles CA, USA.

$\mathrm{J}$ Gen Intern Med 34(11):2329-30

DOI: $10.1007 / \mathrm{s} 11606-019-05243-9$

() Society of General Internal Medicine 2019

\section{INTRODUCTION}

Plagiarism is one type of a professionalism breach, and it has been reported to occur in the personal statements of residency applicants. ${ }^{1,2}$ As there is no information in the literature about plagiarism in the personal comments essays of medical school applicants, the purpose of this study is to determine the rate of plagiarism in the personal comments essays of applications to an allopathic medical school in the United States (US).

\section{METHODS}

This study was approved by the West Virginia University (WVU) Institutional Review Board. Personal comments essays had to be submitted to the American Medical College Application Service (AMCAS) for the WVU School of Medicine (WVU SoM) from 2012 to 2017 for inclusion. Essays of students enrolled at WVU SoM were excluded. The plagiarism detection software, Turnitin (Oakland, CA, USA), which contains a database of approximately 70 billion resources and effectively detects exactly matching written content ${ }^{3}$ was used to screen for plagiarism in the de-identified essays.

The Turnitin software results of 600 screened personal comments essays were reviewed by four investigators (LSN, MCV, AML, KKY) and judged as "plagiarized low" if a match of content to an existing work was less than $10 \%$, and judged as "plagiarized high" if a match of content was $10 \%$ or greater.

\section{STATISTICAL METHODS}

The sample size determination $(\mathrm{n} 1=\mathrm{n} 2=300)$ was based on the hypothesis that the rate of plagiarism (specifically, "plagiarized high") in the first group (n1 = US applicants) would be $7.5 \%$, and $15 \%$ in the second group (n2 = non-US applicants), using the results of residency studies as a guide. ${ }^{1,2}$

Published online August 6, 2019
With a significance level of .05 , two samples of 300 yield a power of approximately $83 \%$. Pearson chi-square tests were used to compare proportions between the two groups and for continuous variables, Student's $t$ test was used to compare means between the two groups, and Mann-Whitney rank sum test for ordinal data between groups. An alpha of 0.05 was used to determine statistical significance in all inferences. All statistical calculations were carried out using JMP/V14 (SAS Institute, Cary, NC).

\section{RESULTS}

The "plagiarized high" rate was $2 \%$ for both groups. There were no significant differences in the "plagiarized low" rate (22\% and $25 \%$ for US and non-US respectively) and the percentages of plagiarized content per essay (Table 1). Essay contents detected as plagiarism in the "plagiarized low" category were names of organizations, titles of individuals, common sayings, and the use of quotes. Content in "plagiarized high" essays included descriptions of memorable experiences. Sources of plagiarized work originated from websites such as "samplepersonalstatement.org," "usingenglish.com," or "essayedge.com."

\section{DISCUSSION}

Our study is the first work to report the rate of plagiarism in the personal comments essays of medical school applicants. The $2 \%$ rate of plagiarism ("plagiarized high") in both US and nonUS AMCAS applicants is less than the reported rates in personal statements of applicants to certain residency programs. ${ }^{1,2}$ Parks and colleagues discovered that $13.6 \%$ of personal statements from non-US medical school graduates and $4.0 \%$ from US medical school graduates contained plagiarized material in applications to their anesthesiology residency program. ${ }^{2}$ As a result of their study, they now screen the personal statements of every applicant and reject those found to have plagiarism. Segal et al. discovered plagiarism in 5.2\% ( $95 \%$ CI, $4.6 \%$ to $5.9 \%$ ) of statements submitted to their five 
Table 1 Characteristics of Applicants and Rates of Plagiarism

\begin{tabular}{|c|c|c|c|}
\hline & $\mathrm{US}(n=300)$ & non-US $(n=300)$ & $P$ value \\
\hline Gender & & & 0.62 \\
\hline Male: $n(\%)$ & $165(55 \%)$ & $159(53 \%)$ & - \\
\hline Female: $n(\%)$ & $135(45 \%)$ & $141(47 \%)$ & - \\
\hline Age $($ years $\pm \mathrm{SD})$ & $26.5 \pm 3.4$ & $26.5 \pm 3.7$ & 0.7 \\
\hline Matriculated to medical school: $n(\%)$ & $113(38 \%)$ & $55(18 \%)$ & $<0.001$ \\
\hline STEM major: $n(\%)$ & $274(91 \%)$ & $291(97 \%)$ & 0.003 \\
\hline Highest degree obtained & & & 0.09 \\
\hline None: $n(\%)$ & $1(0 \%)$ & $1(0 \%)$ & - \\
\hline Bachelor: $n(\%)$ & $257(86 \%)$ & $238(79 \%)$ & - \\
\hline Master: $n(\%)$ & $41(14 \%)$ & $55(18 \%)$ & - \\
\hline PhD: $n(\%)$ & $1(0 \%)$ & $6(2 \%)$ & - \\
\hline No. of essays with plagiarism: $n(\%)$ & $73(24 \%)$ & $81(27 \%)$ & 0.45 \\
\hline Plagiarized low: $n(\%)$ & $65(22 \%)$ & $76(25 \%)$ & - \\
\hline Plagiarized high: $n(\%)$ & $8(2 \%)$ & $5(2 \%)$ & - \\
\hline Percent matched content: median (range) & $2(1-98)$ & $2(1-29)$ & 0.24 \\
\hline Plagiarized low: median (range) & $2(1-7)$ & $2(1-7)$ & - \\
\hline Plagiarized high: median (range) & $24(10-98)$ & $18(10-29)$ & - \\
\hline
\end{tabular}

STEM, science, technology, engineering, and mathematics

Plagiarized low $=$ a match of content to an existing work was less than $10 \%$

Plagiarized high $=$ a match of content to an existing work was $10 \%$ or greater

Percent matched content $=$ percent of matched content discovered per essay

largest residency programs. ${ }^{2}$ The plagiarism rate was substantially higher for international applicants versus US applicants (14\% vs. $2 \%$, respectively). ${ }^{1}$

The main take away points from our study is that the rate of plagiarism detected in the personal essays of medical school applicants is relatively low when the Turnitin software is employed, and less in comparison with reported plagiarism in residency applications. Another unique finding is that in contrast to data reported from residency applications, there was no increased amount of plagiarism in non-US applications versus US applications. Since plagiarism has been found to be more prevalent in residency applications, our study reinforces the findings in published reports that indicate professionalism erodes as aspiring physicians proceed higher in medical training. ${ }^{4}$ The main limitation of our study is that all plagiarism, including semantic plagiarism ${ }^{3}$ and ghostwriting, ${ }^{5}$ could not be detected by the software.

Corresponding Author: Linda S. Nield, MD; Department of Medical EducationWest Virginia University School of Medicine, Morgantown WV, USA (e-mail: lnield@hsc.wvu.edu).

\section{Compliance with Ethical Standards:}

Conflict of Interest: The authors declare that they do not have a conflict of interest.

\section{REFERENCES}

1. Segal S, Gelfand BJ, Hurwitz S, Berkowitz L, Ashley SW, Nadel ES, Katz JT. Plagiarism in residency application essays. Ann Intern Med. 2010;153(2): 112-20.

2. Parks LJ, Sizemore DC, Johnstone RE. Plagiarism in Personal Statements of Anesthesiology Residency Applicants. A A Case Rep. 2016;6(4):103-5.

3. Walchuk $\mathbf{K}$. An Examination of the efficacy of the plagiarism detection software program Turnitin. Thesis for the Degree of Master of Education. Graduate Department of Education in the University of Ontario Institute of Technology. Copyright 2016. Available at: https://ir.library.dc-uoit.ca/ bitstream/10155/717/1/Walchuk_Kevin.pdf. Accessed on April 17, 2017.

4. Mostaghimi A, Olszewski AE, Bell SK, Roberts DH, Crotty BH. Erosion of digital professionalism during medical students' core clinical clerkships. JMIR MED Educ. 2017;3(1):e9. https://doi.org/10.2196/mededu.6879.

5. Knapp JC, Hulbert AM. Academic Dishonesty. In:Ghostwriting and the Ethics of Authenticity. New York: Palgrave Macmillan; 2017:85-105.

Publisher's Note Springer Nature remains neutral with regard to jurisdictional claims in published maps and institutional affiliations. 